\title{
ARTICLE
}

\section{Method Validation and Determination of Leachable Metals from Infusion and Transfusion Medical Devices}

\author{
Alexandra Janine Schuh ${ }^{1}$, Dirce Pozebon ${ }^{2 *}$ iD \\ ${ }^{1}$ Pontifícia Universidade Católica do Rio Grande do Sul (PUCRS), Avenida Ipiranga, 681, 90619-900, Porto \\ Alegre, RS, Brazil \\ 2Instituto de Química, Universidade Federal do Rio Grande do Sul, Av. Bento Gonçalves, 9500, 91501-970, \\ Porto Alegre, RS, Brazil
}

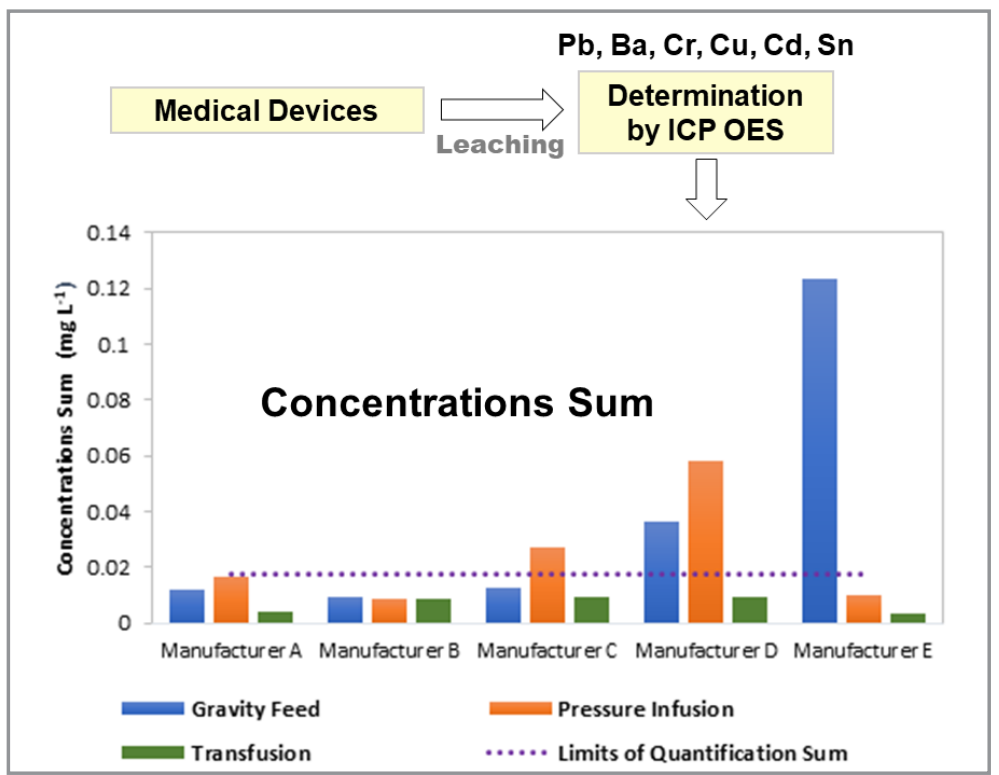

This work deals with method validation for regulated metals $(\mathrm{Cd}, \mathrm{Pb}, \mathrm{Ba}, \mathrm{Sn}, \mathrm{Cr}$ and $\mathrm{Cu})$ determination in infusion and transfusion medical devices. The metals were extracted with water at $(37 \pm 1){ }^{\circ} \mathrm{C}$ followed by their determination in the extract by using inductively coupled plasma optical emission spectrometry (ICP OES). The validated method was applied in the analysis of infusion and transfusion devices commercialized in Brazil to verify compliance with current legislation, which establishes that the sum of $\mathrm{Pb}, \mathrm{Ba}, \mathrm{Sn}, \mathrm{Cr}$ and $\mathrm{Cu}$ in the extract must not exceed $1 \mathrm{mg}$ $\mathrm{L}^{-1}$ and that of $\mathrm{Cd}$ must not $0.1 \mathrm{mg} \mathrm{L}^{-1}$. Samples from five manufacturers of infusion and transfusion devices, produced in Brazil or imported, were analysed. The results of the analysis showed that all devices complied with the legislation, whereas the sum of $\mathrm{Pb}, \mathrm{Ba}$, $\mathrm{Sn}, \mathrm{Cr}$ and $\mathrm{Cu}$ concentrations and that of $\mathrm{Cd}$ in the extract were lower than the maximum permissible; Cd was not detected in any sample extract and the sum of the other elements was $<0.14 \mathrm{mg} \mathrm{L}^{-1}$ in all extracts of the analysed samples.

Keywords: method validation, regulated metals, infusion and transfusion medical devices

\section{INTRODUCTION}

A multitude of disposable medical devices (DMDs) such as infusion and transfusion devices, catheters and syringes are widely used in clinical practice [1,2]. The materials composing DMDs must be biocompatible and allow the intended function without causing undesirable side effects such as necrosis to patients and allergic reactions to patients and medical staff $[3,4]$. Moreover, such materials must be quite 
pure because impurities present can directly enter the bloodstream of patients and cause intoxication of them. The DMDs are composed of polymers that are considered safe, but they may be harmful to patients and medical staffs $[1,2,5,6]$. Therefore, the quality of DMDs must be controlled. The DMS are mainly constituted of silicone, polyvinyl chloride (PVC), latex rubber [5,6] and additives. Different processes are involved in DMDs manufacturing, which are usually not disclosed by the manufacturers and potential contaminants not informed.

Besides insufficient sterility and structural defects, DMDs can release microparticles, toxic elements, or compounds that are then transferred to patients under treatment. As such, the DMDs toxicity is apparently related to multiple leachable compounds that are released from the DMDs during their clinical use [2]. Infusion devices are usually in prolonged contact with patients and can induce local inflammation, allergic reactions, systemic toxicity, and infections $[1,2,4-6]$. Furthermore, whatever is released by the infusion devices goes directly into the patient's bloodstream $[1,4]$.

Infusion and transfusion devices are currently evaluated with respect to cytotoxicity, sensitization, intracutaneous irritation or reaction, acute systemic toxicity, and hemocompatibility. Recommendations for this type of devices are described in the ISO 8536 series for infusion devices and in the ISO 1135 series for transfusion devices [7-10]. Research about infusion and transfusion devices side effects has dealt with biological aspects $[1-3,5,6]$ and any research regarding the presence of toxic elements that could be leached from these devices has not been published so far.

Surveillance of production and commercialization of transfusion and infusion devices in Europe and The United States are conducted according to the Directive (EU) 2017/745 [11] and FDA (Food and Drug Administration) [12], respectively. The National Health Surveillance Agency (ANVISA) is responsible for such surveillance in Brazil [13], whereas the certification of DMDs (produced in Brazil or imported) is conducted by the National Metrology Institute, Quality and Technology (INMETRO) [14]. The laboratories that carry out the analysis for certification of DMDs must be accredited to the Brazilian Network of Testing Laboratories [14,15]. One of the requirements for certification of diffusion and infusion devices is the determination of leachable $\mathrm{Ba}, \mathrm{Cr}, \mathrm{Cu}, \mathrm{Pb}, \mathrm{Sn}$ and $\mathrm{Cd}$; the sum of $\mathrm{Ba}, \mathrm{Cr}, \mathrm{Cu}, \mathrm{Pb}$, Sn concentrations in the leached must not exceed $1 \mathrm{mg} \mathrm{L}^{-1}$ and that of $\mathrm{Cd}$ must not $0.1 \mathrm{mg} \mathrm{L}^{-1}$. Such determination shall be carried out following a validated method.

Atomic spectrometry techniques such as atomic absorption spectrometry (AAS), inductively coupled plasma mass spectrometry (ICP-MS) and inductively coupled plasma optical emission spectrometry (ICP $\mathrm{OES}$ ) can be employed for $\mathrm{Ba}, \mathrm{Cr}, \mathrm{Cu}, \mathrm{Pb}, \mathrm{Sn}$ and $\mathrm{Cd}$ determination in the leachate of infusion and transfusion devices. The laboratory that performs the analysis must validate non-standard methods, that is, methods that are outside the intended scope (methods planned/developed in the laboratory or modified standard methods) [14-17]. An analytical method can be validated through interlaboratory analysis or not (single laboratory approach), depending on the interests involved $[17,18]$. Selectivity, linearity (including the working range), sensitivity, limit of detection (LOD), limit of quantification (LOQ), bias, accuracy, overall uncertainty, precision, and robustness $[17,18]$ are parameters evaluated in a method validation. Robustness assessment is optional and generally not required for well-established methods [19]. The purpose of validation is to guarantee that the candidate method provides results that are equivalent to those provided by the standard method [18].

A method of DMDs (infusion and transfusion devices in the present case) analysis was validated in the present work using ICP OES for determination of regulated metals; leachable $\mathrm{Cd}, \mathrm{Pb}, \mathrm{Ba}, \mathrm{Sn}, \mathrm{Cr}$ and $\mathrm{Cu}$ were determined. The validated method was applied in the analysis of infusion and transfusion devices used in Brazil to verify the compliance with current legislation.

\section{MATERIALS AND METHODS Instrumental}

For elemental analysis, an ICP OES spectrometer (model ICAP 6200, dual view, Thermo Scientific) was employed. Argon with purity of $99.9992 \%$ (White Martins/Praxair, Brazil) was used as principal, auxiliary and nebulizer gas. Instrumental parameters and the operating conditions of ICP OES are summarized in Table I. 
Table I. Instrumental and operating conditions of ICP OES and spectral lines monitored

\begin{tabular}{ll}
\hline Parameter & Settings \\
\hline Radio frequency power & $1150 \mathrm{~W}$ \\
Plasma gas flow rate $(\mathrm{L} \mathrm{min}-1)$ & 15.0 \\
Auxiliary gas flow rate $\left(\mathrm{L} \mathrm{min}^{-1}\right)$ & 0.5 \\
Nebulizer gas flow rate $\left(\mathrm{L} \mathrm{min}^{-1}\right)$ & 0.5 \\
Peristaltic pump speed & $45 \mathrm{rpm}$ \\
Plasma view & Axial \\
Nebulizer & Concentric \\
Spray chamber & Cyclonic \\
Replicates & 7 \\
Wavelength $(\mathrm{nm})$ & Pb II (220.3 nm); Sn I (189.9 nm); Ba II $(233.5 \mathrm{~nm}) ; \mathrm{Cr}$ II \\
\hline
\end{tabular}

\section{Standards, reagents, and solutions}

The following certified standard solutions from Accustandard were used for preparation of calibration solutions: ICP-29N-1 containing (1.014 \pm 0.024$) \mathrm{mg} \mathrm{kg}^{-1}$ of Pb; ICP-63N-1 containing $(0.9881 \pm 0.0024) \mathrm{mg}$ $\mathrm{kg}^{-1}$ of Sn; ICP-4N-1 containing (0.986 \pm 0.002$) \mathrm{mg} \mathrm{kg}^{-1}$ of Ba; ICP-13N-1 containing (1.015 \pm 0.002$) \mathrm{mg}$ $\mathrm{kg}^{-1}$ of $\mathrm{Cr}$; ICP-08N-1 containing $(1.013 \pm 0.002) \mathrm{mg} \mathrm{kg}^{-1}$ of $\mathrm{Cd}$; and ICP-15N-1 containing $(0.987 \pm 0.024)$ $\mathrm{mg} \mathrm{kg}^{-1}$ of $\mathrm{Cu}$. To evaluate the accuracy of the method, aliquots of samples were spiked with the following certified reference materials from NIST (National Institute of Standards and Technology): SRM 3128 $(9.995 \pm 0.014) \mathrm{mg} \mathrm{kg}^{-1} \mathrm{~Pb}$; SRM $3161 \mathrm{a}-(10.011 \pm 0.025) \mathrm{mg} \mathrm{kg}^{-1} \mathrm{Sn} ; \mathrm{SRM} 3104 \mathrm{a}-(6.994 \pm 0.017) \mathrm{mg}$ $\mathrm{kg}^{-1} \mathrm{Ba}$; SRM 3112a - (10.009 \pm 0.020$) \mathrm{mg} \mathrm{kg}^{-1} \mathrm{Cr}$; SRM $3108-(10.007 \pm 0.027) \mathrm{mg} \mathrm{kg}^{-1} \mathrm{Cd}$; and SRM $3114-(10.005 \pm 0.024) \mathrm{mg} \mathrm{kg}^{-1} \mathrm{Cu}$.

Nitric acid $\left(\mathrm{HNO}_{3} 65 \%\right.$ from Merck) was used in calibration solutions. All solutions and samples were prepared using ultrapure water (minimum resistivity of $18.2 \mathrm{M} \Omega \mathrm{cm}$ (purified in a Millipore Direct-Q Ultrapure system), type 1 according to ISO 3696 [20].

Volumetric flasks (Brand, Germany), digital micropipettes (Transpette, Brand, Germany) and analytical balance (AUX320, Shimadzu) calibrated to the Brazilian calibration network (RBC) were used.

\section{Samples and procedure}

Samples of infusion and transfusion devices produced by five different manufacturers (two national and three international) and commercialized in Brazil were analysed: 45 gravimetric infusion devices, 45 infusion devices for connection to pumps, and 45 transfusion devices. The manufacturers were identified by letters A, B, C, D and E.

Figure 1 shows a scheme of an infusion device for use in pumps. Infusion devices and transfusion devices are similar; the main differences are in the drip chamber (6) and fluid filter (7), being this filter more porous and larger in transfusion devices.

Infusion and transfusion devices were leached in a closed way encompassing three devices of the same model connected in series (through silicone tubes) to a $300 \mathrm{~mL}$-borosilicate glass flask containing $250 \mathrm{~mL}$ of purified water (see Figure 2). This water was heated at $(37 \pm 1)^{\circ} \mathrm{C}$, passed through the three 
devices and then returned to the flask under heating. A peristaltic pump was employed to transport the water at a flow rate of $1 \mathrm{~L} \mathrm{~h}^{-1}$ for $2 \mathrm{~h}$ continuously. This procedure was carried out following reference [7]. The extract was transferred to a $250 \mathrm{~mL}$-volumetric flask, to which $12.5 \mathrm{~mL}$ of $\mathrm{HNO}_{3}$ were added and the volume adjusted to the mark by adding water. Then, $\mathrm{Cd}, \mathrm{Pb}, \mathrm{Ba}, \mathrm{Sn}, \mathrm{Cr}$, and $\mathrm{Cu}$ were determined in this solution according to the validated method.
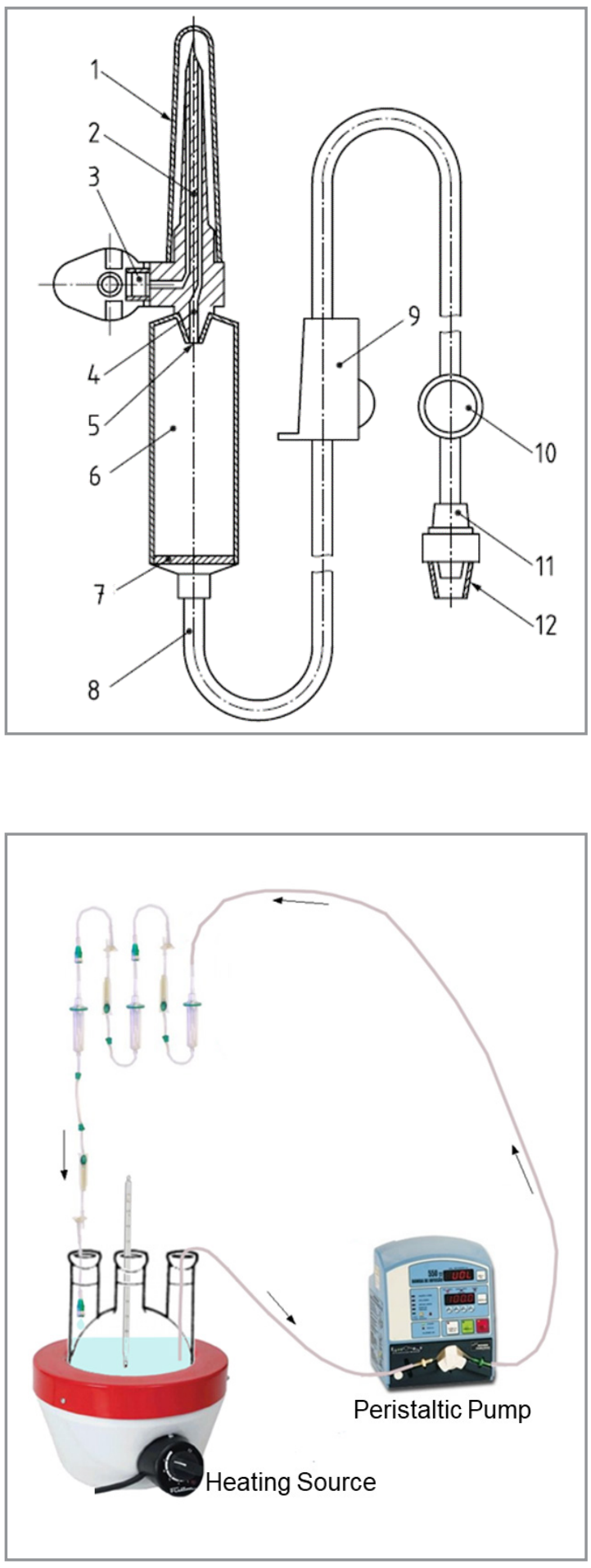

Figure 1. Scheme of an infusion medical device. 1: protector; 2: perforating tip; 3: air filter; 4: fluid channel; 5: dripper; 6: drip chamber; 7: fluid filter; 8: transfer tube; 9: flow regulator; 10: lateral injector; 11: luer lock connector; 12: protector. (Reprinted with permission from Associação Brasileira de Normas Técnicas. ABNT NBR ISO 8536-4. Equipamento de infusão para uso médico. Parte 4: Equipos de infusão para uso único, alimentação por gravidade, 2011. ISO 8536-4, 2019 [7].)

Figure 2. Scheme illustrating the leaching procedure of infusion and transfusion devices; arrows indicate the circulating water direction. 


\section{Method Validation}

Selectivity, linearity, bias, sensitivity, LOD, LOQ, accuracy, uncertainty, and precision were evaluated for method validation, following Eurachem guidelines [18].

Two calibration curves were prepared for each analyte; solution calibrations were prepared in $5 \%(\mathrm{v} / \mathrm{v})$ $\mathrm{HNO}_{3}$ for one of the calibration curves and in the sample leached medium $+5 \%(\mathrm{v} / \mathrm{v}) \mathrm{HNO}_{3}$ for the other.

Each calibration curve was composed of seven points corresponding to 7 solutions with different concentrations of the analytes: 100, 200, 300, 400, 500, 600 and $700 \mathrm{\mu g} \mathrm{L}^{-1}$ of Pb, Sn, Ba, Cr and Cu; and $10,25,50,75,100,125$ and $150 \mathrm{~g} \mathrm{~L} \mathrm{~L}^{-1}$ of $\mathrm{Cd}$. The analytes concentrations in the prepared calibration solutions were equidistant to avoid leverage effect in calibration curves.

The Snedecor F-test was applied to assess the variance homogeneity and the analysis of variance (ANOVA) was applied to assess the similarity of the calibration curves [17,21]. The slopes of calibration curves were compared to evaluate the selectivity of the method. In the linearity evaluation, outlier values were detected and excluded using the Grubbs test $[19,22]$. The linear regression coefficient $(r)$ was then calculated, and it was acceptable if $r \geq 0.9950$.

The LOD and LOQ were calculated using Equations (1) and (2), respectively:

$$
\begin{array}{ll}
L O D=C+3 s & \text { Equation (1) } \\
L O Q=C+10 s & \text { Equation (2) }
\end{array}
$$

where $C$ is the mean concentration of ten consecutive analyte determinations in the sample blank (leached from a sample where none of the analytes were detected) and $s$ is the standard deviation of them.

Aliquots of samples leachate were fortified with known amounts of the analytes at two concentration levels and within the concentration range of the respective calibration curves for accuracy evaluation. Analyte recovery in the range of 80 to $110 \%$ was accepted [17].

The method precision was evaluated through repeatability, intermediate precision, and reproducibility $[17,21]$. As such, the coefficient of variation (CV) and ANOVA of data obtained in analyses conducted by different analysts in different days and participation in an Interlaboratory program were considered. The interlaboratory program was coordinated by the Metrological Network of Rio Grande do Sul, Brazil. This interlaboratory program was part of a project of the Brazilian Technology System (SIBRATEC) that assists the development of technological services in metrology, standardization and conformity assessment approved by the Ministry of Science, Technology and Innovations (MCTIC) of Brazil.

The semi-empirical model was followed in the evaluation of the expanded uncertainty $(U)$ of the method. The uncertainty was obtained by multiplying the combined standard uncertainty $\left(\mu C_{a}\right)$ by a coverage factor $(k=2)$, for a confidence interval of $95.45 \%[23,24]$. $U$ was calculated using the linear squares fit, assuming that the uncertainties of the values on the abscissa are considerably smaller than the uncertainty of the values in the ordinate. The contribution of calibration standards to the overall uncertainty was considered negligible; $\mu C_{a}$ was calculated by Equation (3) and the standard deviation of residues by Equations (4) and (5).

$$
\begin{array}{rlr}
\mu C_{a} & =\frac{S}{b_{1}} \sqrt{\frac{1}{n_{a}}+\frac{1}{n}+\frac{\left(C_{a}-\bar{C}\right)^{2}}{S_{x x}}} & \text { Equation (3) } \\
S=\frac{\sum_{j=1}^{n}\left[Y_{j}-\left(b_{0}+b_{1}, C_{j}\right)\right]^{2}}{n-2} & \text { Equation (4) }
\end{array}
$$




$$
S_{x x}=\sum_{j=i}^{n}\left(C_{j}-\bar{C}\right)^{2} \quad \text { Equation (5) }
$$

where:

$b_{1}$ : angular coefficient of the linear equation of calibration curve (slope)

$b_{0}$ : intercept point on the ordinate axis (linear coefficient)

$Y_{j}: j^{\text {th }}$ measurement of the intensity of the $i^{\text {th }}$ calibration solution

$S$ : residual standard deviation

$n:$ number of measurements for calibration

$n_{a}$ : number of measurements performed for the sample under analysis

$C_{a}$ : concentration of the analyte in the sample solution

$\bar{C}$ : avarege value for each calibration solution (for $n$ measurements)

$i$ : index for the number of calibration solution

$j:$ index for the number of measurements to obtain the calibration curve

\section{RESULTS AND DISCUSSION Method Validation}

Selectivity

In method validation it is necessary to prove that the method is selective even if any matrix effect is not expected. According to normative documents [17-20], selectivity is evaluated by calibration curves comparison. This makes evident that there is matrix effect or not. Calibration curves were obtained from calibration solutions prepared in $5 \%(\mathrm{v} / \mathrm{v}) \mathrm{HNO}_{3}$ in presence or absence of sample leached medium. The angular coefficient (slope) values of the linear regression equation of the calibration curves obtained were compared by ANOVA and they did not differ significantly (see Table II). Besides, parallelism of lines was observed for the two calibration curves. Therefore, the calibration solutions could be prepared in $5 \%(\mathrm{v} / \mathrm{v}) \mathrm{HNO}_{3}$ solely because the sample matrix does not interfere. The homogeneity of variance for each concentration level also demonstrated the absence of matrix effect. Additionally, the homogeneity of variance by concentration level (Table III) demonstrated that the sample matrix does not interfere regardless of the concentration. Thus, the method was considered selective, that is, the analyte determination does not depend on other substances present in the sample leached.

\section{Linearity}

The linear dynamic range of ICP OES is about five orders of magnitude. Even so, linearity must be evaluated because this is required in a method validation, according to normative documents [17-20]. As previously mentioned, calibration curves were composed of 7 equidistant points to avoid leverage. For each point 7 solutions were prepared, and the mean intensity value plotted as a function of concentration. The correlation coefficient $(r)$ values were $\geq 0.9950$ (Table II), which was acceptable. The residues (difference among the obtained $y$ value and the predicted y value) were randomly distributed and close to zero, denoting the linearity of the established working range.

Table II. Calibration curve parameters and results of ANOVA; $F_{\text {critical }}=4.60$; confidence level of $95.45 \%$

\begin{tabular}{lcccccc}
\hline Parameters & Pb & Sn & Ba & Cr & Cu & Cd \\
\hline Slope - 5\% (v/v) $\mathrm{HNO}_{3}$ & 1519 & 1902 & 4813 & 15354 & 18216 & 11062 \\
Slope - sample leached $+5 \%(\mathrm{v} / \mathrm{v}) \mathrm{HNO}_{3}$ & 1570 & 1983 & 4946 & 17130 & 19931 & 11249 \\
$\mathrm{r}-5 \%(\mathrm{v} / \mathrm{v}) \mathrm{HNO}_{3}$ & 0.9998 & 0.9980 & 0.9984 & 0.9984 & 0.9982 & 0.9959 \\
\hline
\end{tabular}


Table II. Calibration curve parameters and results of ANOVA; $F_{\text {critical }}=4.60$; confidence level of $95.45 \%$ (Continuation)

\begin{tabular}{lcccccc}
\hline Parameters & $\mathrm{Pb}$ & $\mathrm{Sn}$ & $\mathrm{Ba}$ & $\mathrm{Cr}$ & $\mathrm{Cu}$ & $\mathrm{Cd}$ \\
\hline $\mathrm{r}$ - sample leached $+5 \%(\mathrm{v} / \mathrm{v}) \mathrm{HNO}_{3}$ & 0.9989 & 0.9999 & 0.9998 & 0.9983 & 0.9979 & 0.9960 \\
$\mathrm{~F}_{\text {calculated }}$ & 0.018 & 0.04 & 0.53 & 0.53 & 0.86 & 0.05 \\
$\mathrm{P}_{\text {value }}$ & 0.90 & 0.84 & 0.48 & 0.48 & 0.37 & 0.99 \\
\hline
\end{tabular}

Table III. Values of $\mathrm{F}_{\text {calculated }}$ for each concentration level of calibration curves; 12 degrees of freedom ( $n-2)$ and confidence level of $95.45 \% ; F_{\text {critical }}=4.28$

\begin{tabular}{ccccccc}
\hline Calibration Solutions & $\mathbf{P b}$ & $\mathbf{S n}$ & $\mathbf{B a}$ & $\mathbf{C r}$ & $\mathbf{C u}$ & $\mathbf{C d}$ \\
\hline Blank & 1.08 & 0.02 & 0.23 & 2.47 & 0.32 & 0.39 \\
1 & 0.18 & 0.18 & 0.15 & 3.17 & 2.58 & 2.45 \\
2 & 1.36 & 0.29 & 0.11 & 0.99 & 0.61 & 2.96 \\
3 & 0.45 & 0.19 & 0.01 & 0.13 & 0.17 & 0.97 \\
4 & 0.75 & 0.19 & 0.18 & 0.12 & 0.37 & 3.96 \\
5 & 1.26 & 0.09 & 0.20 & 0.39 & 0.67 & 3.51 \\
6 & 0.22 & 2.70 & 0.22 & 1.42 & 1.39 & 3.16 \\
7 & 2.98 & 0.13 & 0.38 & 3.99 & 3.72 & 0.93 \\
\hline
\end{tabular}

\section{Accuracy}

The accuracy was assessed through the analyte recovery in spiked sample and normalized error. The obtained results are presented in Table IV where one can observe the analyte recovery and the normalized error were $80-110 \%$ and less than $\leq 1$, respectively. These are established values for the accuracy acceptance $[17,21,25]$ and, therefore, the method can be considered accurate.

Table IV. Normalized error and analyte recovery; samples were spiked with aliquots of NIST SRMs

\begin{tabular}{cccc}
\hline Analyte & $\begin{array}{c}\text { Fortification Level } \\
\left(\mathbf{m g ~ L}^{-1}\right)\end{array}$ & Recovery (\%) & Normalized Error \\
\hline $\mathrm{Pb}$ & 0.200 & 104 & 0.169 \\
& 0.500 & 100 & 0.047 \\
$\mathrm{Sn}$ & 0.200 & 101 & 0.043 \\
$\mathrm{Ba}$ & 0.500 & 100 & 0.048 \\
& 0.200 & 100 & 0.043 \\
\hline
\end{tabular}


Table IV. Normalized error and analyte recovery. Samples were spiked with aliquots of NIST SRMs (Continuation)

\begin{tabular}{cccc}
\hline Analyte & $\begin{array}{c}\text { Fortification Level } \\
\left(\mathbf{m g ~ L}^{-1}\right)\end{array}$ & Recovery (\%) & Normalized Error \\
\hline \multirow{2}{*}{$\mathrm{Cr}$} & 0.200 & 103 & 0.280 \\
& 0.500 & 104 & 0.888 \\
$\mathrm{Cu}$ & 0.200 & 102 & 0.127 \\
& 0.500 & 101 & 0.189 \\
$\mathrm{Cd}$ & 0.050 & 104 & 0.306 \\
& 0.100 & 106 & 0.952 \\
\hline
\end{tabular}

\section{Precision}

Precision was assessed through repeatability, intermediate precision, and reproducibility. To access repeatability, two solutions (A and B) named "blind samples" were analysed. The analytes concentrations in these solutions were close to those in the calibration solutions corresponding to the intermediate points of the calibration curves; the analytes concentrations in the "blind samples" were unknown by the analysts. The CV of the obtained data (Table V) met the repeatability acceptance criteria, considering the concentration range involved $[17,21,25,26]$. To assess the intermediate precision (which represents the variability of the results in a laboratory) two analysts conducted the samples analyses in different days. To this end, they prepared calibration curves and spiked aliquots of samples to obtain 0.050 or $0.100 \mathrm{mg} \mathrm{L}^{-1}$ of $\mathrm{Cd}$, and 0.200 or $0.500 \mathrm{mg} \mathrm{L}^{-1}$ of the other elements. Results obtained by the two analysts were submitted to ANOVA that demonstrated they were not different $\left(F_{\text {calculated }}<F_{\text {critical }}\right.$ and $\left.p>0.05\right)$.

Table V. Coefficient of variation (CV) in "blind samples" analysis, accepted values [17-21] and results obtained in the analyses conducted by two analysts in different days; $n=5$ for each element and sample

\begin{tabular}{|c|c|c|c|c|c|}
\hline \multirow{2}{*}{ Analyte } & \multirow{2}{*}{ Blind Samples } & \multirow{2}{*}{$\begin{array}{c}\text { Obtained CV } \\
(\%)\end{array}$} & \multirow{2}{*}{$\begin{array}{c}\text { Accepted CV } \\
(\%)\end{array}$} & \multicolumn{2}{|c|}{ Concentration Found $\left(\mathrm{mg} \mathrm{L}^{-1}\right)$} \\
\hline & & & & Analyst 1 & Analyst 2 \\
\hline \multirow{2}{*}{$\mathrm{Pb}$} & $A$ & 0.19 & $\leq 11$ & 0.207 & 0.192 \\
\hline & $\mathrm{B}$ & 0.98 & $\leq 11$ & 0.502 & 0.491 \\
\hline \multirow{2}{*}{ Sn } & $A$ & 0.84 & $\leq 11$ & 0.202 & 0.213 \\
\hline & B & 1.01 & $\leq 11$ & 0.503 & 0.509 \\
\hline \multirow{2}{*}{$\mathrm{Ba}$} & $A$ & 0.25 & $\leq 11$ & 0.201 & 0.203 \\
\hline & B & 0.18 & $\leq 11$ & 0.508 & 0.494 \\
\hline \multirow{2}{*}{$\mathrm{Cr}$} & $A$ & 1.45 & $\leq 11$ & 0.206 & 0.204 \\
\hline & B & 0.63 & $\leq 11$ & 0.519 & 0.501 \\
\hline \multirow{2}{*}{$\mathrm{Cu}$} & $A$ & 1.65 & $\leq 11$ & 0.205 & 0.202 \\
\hline & B & 0.06 & $\leq 11$ & 0.507 & 0.491 \\
\hline \multirow{2}{*}{$\mathrm{Cd}$} & A & 0.19 & $\leq 15$ & 0.052 & 0.051 \\
\hline & B & 0.38 & $\leq 15$ & 0.105 & 0.100 \\
\hline
\end{tabular}


The method reproducibility was confirmed through participation in an interlaboratory program involving three laboratories. Results for the laboratory where the present method has been validated are summarized in Table VI for one sample of transfusion device whose leached has been spiked and distributed to participating laboratories of the interlaboratory program. A value of z-score lower than 2 , in module, means that the results found are satisfactory; between 2 and 3 they are "questionable"; and higher than 3 they are "unsatisfactory". As can be seen in Table VI, the results were satisfactory.

Table VI. Laboratory performance in the interlaboratory program

\begin{tabular}{cccccc}
\hline Analyte & Found $\left(\mathrm{mg} \mathrm{L}^{-1}\right)$ & CV (\%) & $\begin{array}{c}\text { Accuracy and } \\
\text { Precision }\end{array}$ & Z-score & $\begin{array}{c}\text { Laboratory } \\
\text { Performance }\end{array}$ \\
\hline $\mathrm{Pb}$ & 1.041 & 0.7 & & 1.14 & \\
$\mathrm{Sn}$ & 0.177 & 4.2 & & 0.71 & Satisfactory \\
$\mathrm{Ba}$ & 1.848 & 0.6 & Satisfactory & -0.71 & -0.10 \\
$\mathrm{Cr}$ & 0.507 & 0.6 & & -0.73 & \\
$\mathrm{Cu}$ & 1.589 & 0.5 & & 0.19 \\
$\mathrm{Cd}$ & 0.214 & 1.0 & & \\
\hline
\end{tabular}

\section{Limit of detection and quantification}

The LOD and LOQ of the method were calculated by Equations (1) and (2). As can be observed in Table VII, the sum of $\mathrm{Pb}, \mathrm{Sn}, \mathrm{Ba}, \mathrm{Cu}$ and $\mathrm{Cr}$ concentrations is $\leq 1 \mathrm{mg} \mathrm{L}^{-1}$, and the $\mathrm{Cd}$ concentration is $\leq 0.1 \mathrm{mg}$ $\mathrm{L}^{-1}$. Therefore, the calculated LOQs met the maximum limits allowed for these elements in infusion and transfusion devices. The overall uncertainty was $<4 \%$ for all analytes, which is also satisfactory.

Table VII. Limits of detection (LOD) and quantification (LOQ) of the method

\begin{tabular}{cccc}
\hline Analyte & LOD $\left(\mathrm{mg} \mathrm{L}^{-1}\right)$ & LOQ $\left(\mathrm{mg} \mathrm{L}^{-1}\right)$ & $\begin{array}{c}\text { Relative } \\
\text { Uncertainty (\%) }\end{array}$ \\
\hline $\mathrm{Pb}$ & 0.0031 & 0.0102 & 2.5 \\
$\mathrm{Sn}$ & 0.0010 & 0.0034 & 2.0 \\
$\mathrm{Ba}$ & 0.0019 & 0.0061 & 1.4 \\
$\mathrm{Cr}$ & 0.0012 & 0.0036 & 3.4 \\
$\mathrm{Cu}$ & 0.0005 & 0.0016 & 2.2 \\
$\mathrm{Cd}$ & 0.0001 & 0.0008 & 1.4 \\
\hline
\end{tabular}

\section{Sample Analysis}

The results of the analysis of infusion and transfusion devices are depicted in Figure 3. As shown in this figure, the sum of the metals concentrations was above the LOQs sum for pressure infusion devices from manufacturers $C$ and $D$ and for gravity infusion devices from manufacturers $D$ and $E$. However, the sum of $\mathrm{Pb}, \mathrm{Ba}, \mathrm{Cr}$, Cu and $\mathrm{Sn}$ concentrations in the leached was lower than $1 \mathrm{mg} \mathrm{L}^{-1}$ (the maximum accepted concentration) for all samples and manufacturers. The noteworthy highest value for manufacturer $E$ was 
due to $\mathrm{Sn}$ whose concentration was higher in the leachate of samples from this manufacturer than in the others. Cadmium concentration (not shown in Figure 3) was lower than the LOQ $\left(0.008 \mathrm{mg} \mathrm{L}^{-1}\right)$ in all analysed samples. Thus, Cd concentration followed the legislation which recommends the concentration of this element in the leached must be lower than $0.1 \mathrm{mg} \mathrm{L}^{-1}$.

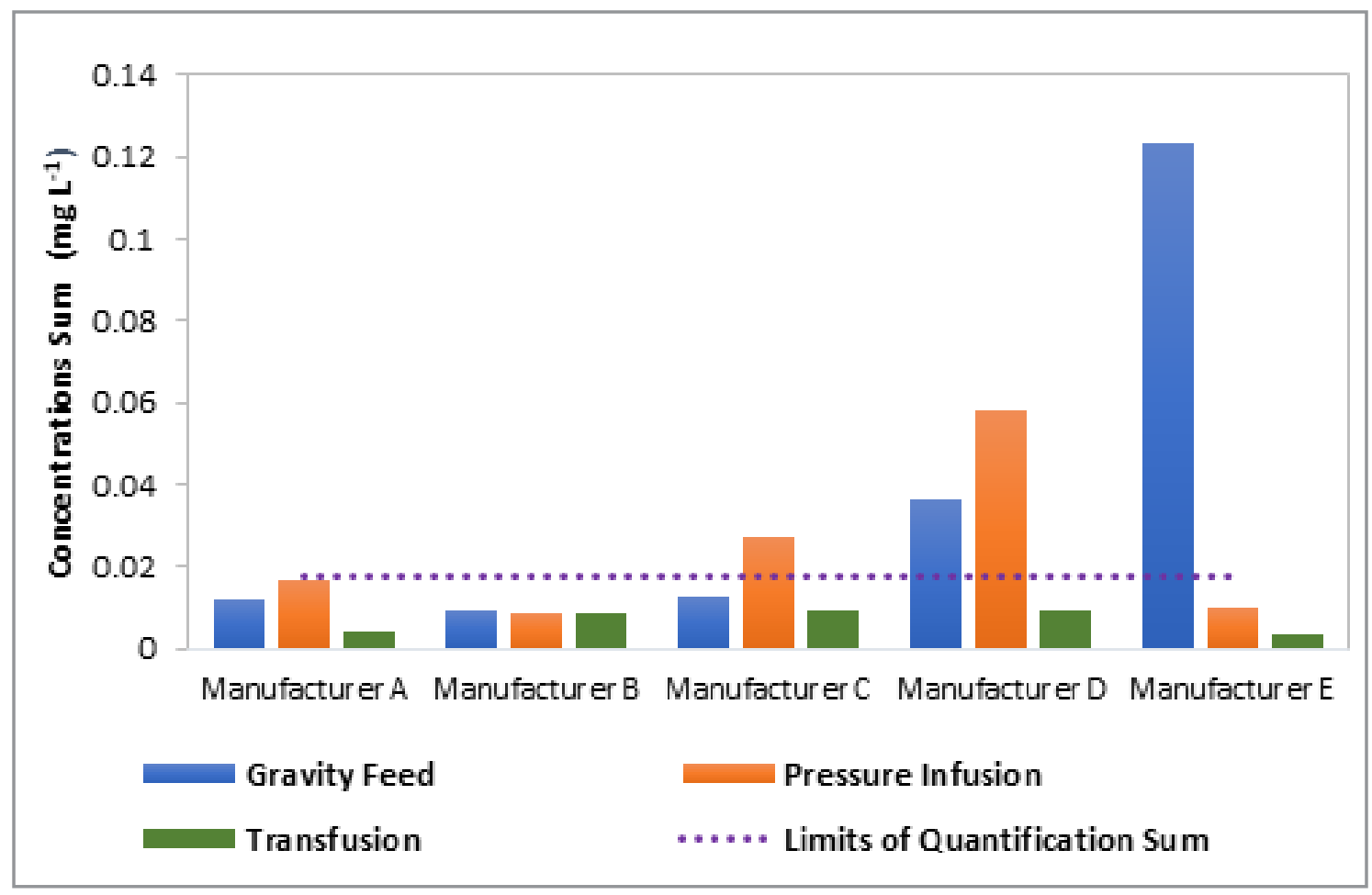

Figure 3. Sum of $\mathrm{Pb}, \mathrm{Ba}, \mathrm{Cr}, \mathrm{Cu}$ and $\mathrm{Sn}$ concentrations in the leachate of infusion and transfusion devices.

\section{CONCLUSIONS}

The validated method is suitable for infusion and transfusion devices analysis with respect to regulated metals determination. The LOQs are adequate and ICP OES can be employed for $\mathrm{Pb}, \mathrm{Ba}, \mathrm{Cr}, \mathrm{Cu}, \mathrm{Cd}$ and Sn determination in the leachate from these devices, and the validated method meets the requirements of the current legislation.

The infusion and transfusion devices commercialized in Brazil, produced in the country or imported, are in accordance with the current legislation, having the expected quality with respect to leachable $\mathrm{Pb}, \mathrm{Ba}$, $\mathrm{Cr}, \mathrm{Cu}, \mathrm{Cd}$ and $\mathrm{Sn}$.

Currently, DMDs like syringes, needles, and transfusion and diffusion devices are regulated and must be certified. However, the regulation should be extended to other DMDs used in Brazil, to ensure the minimum quality necessary regarding leachable toxic elements.

\section{Conflicts of interest}

The authors declare that there is not any conflict of interest.

\section{Acknowledgements}

The authors are grateful to LABELO of PUCRS by providing the necessary infrastructure to carry out the work. 


\section{REFERENCES}

1. Kozlovskaya, L.; Stepensky, D. Int. J. Pharm., 2015, 179 (2), pp 693-701 (https://doi.org/10.1016/j. ijpharm.2014.12.020).

2. Kozlovskaya, L.; Popilski, H.; Gorenbein, P.; Stepensky, D. Int. J. Pharm., 2015, 489 (1-2), pp 285-293 (https://doi.org/10.1016/j.jpharm.2015.04.065).

3. Litman, R. S.; Smith, V. I.; Mainland, P. Pediatr. Anesth., 2017, 28(1) (https://doi.org/10.1111/pan.13279).

4. International Organization for Standardization. ISO 10993-1:2018. Biological evaluation of medical devices - Part 1: Evaluation and testing within a risk management process. Available at: https://scc. isolutions.iso.org/obp/ui\#iso:std:iso:10993:-1:ed-5:v2:en [Accessed April 2021].

5. Dakwar, G. R.; Kaplun, V.; Kojukarov, L.; Gorenbein, P.; Schumacher, I.; Kontorovich, D.; Förster, C.; Beit-Yannai, E.; Stepensky, D. Int. J. Pharm., 2012, 434 (1-2), pp 20-27 (https://doi.org/10.1016/j. ijpharm.2012.05.019).

6. Schumacher, I.; Tsiperman, E.; Tarnopolsky, A.; Raskin, A.; Sigler, E.; Domb, A.J. Polym. Adv. Technol., 2007, 18, pp 207-212 (https://doi.org/10.1002/pat.856).

7. Associação Brasileira de Normas Técnicas (ABNT). ABNT NBR ISO 8536-4. Equipamento de infusão para uso médico. Parte 4: Equipos de infusão para uso único, alimentação por gravidade, 2011. ISO 8536-4, 2019.

8. International Organization for Standardization. ISO 8536-8. Infusion equipment for medical use - Part 8: Infusion sets for single use with pressure infusion apparatus, 2015.

9. International Organization for Standardization. ISO 1135-4:2015. Transfusion equipment for medical use - Part 4: Transfusion sets for single use, gravity feed, 2015.

10. International Organization for Standardization. ISO 1135-5:2015. Transfusion equipment for medical use - Part 5: Transfusion sets for single use with pressure infusion apparatus, 2015.

11. European Union. Directive 2017/45/EEC. Regulation (EU) 2017/745 of the European Parliament and of the Council, amending Directive 2001/83/EC, Regulation (EC) No 178/2002 and Regulation (EC) No 1223/2009 and repealing Council Directives 90/385/EEC and 93/42/EEC. Available at: https:// op.europa.eu/en/publication-detail/-/publication/83bdc18f-315d-11e7-9412-01aa75ed71a1/languageen/format-PDF/source-58036705 [Accessed: December 2020].

12. Food and Drug Administration (FDA). Biocompatibility Testing of Medical Devices - Standards Specific Information for the Accreditation Scheme for Conformity Assessment (ASCA) Pilot Program. Available at: https://www.fda.gov/media/142388/download [Accessed April 2021].

13. Agência Nacional de Vigilância Sanitária (ANVISA). Resolução RDC nº 342 de 06 de março de 2020. Estabelece os requisitos mínimos de identidade e qualidade para os equipos de uso único de transfusão, de infusão gravitacional e de infusão para uso com bomba de infusão. Available at: http:// www.so.com.br/legislacao_anvisa/2020/RDC_342_2020_.pdf [Accessed: September 2020].

14. Instituto Nacional de Metrologia, Qualidade e Tecnologia (Inmetro). Portaria $\mathrm{n}^{\circ} 289$ de 04 de setembro de 2020. Requisitos de Avaliação da Conformidade para Agulhas Hipodérmicas Estéreis para Uso Único e Agulhas Gengivais Estéreis para Uso Único, para Equipos de Uso Único de Transfusão, de Infusão Gravitacional e de Infusão para Uso com Bomba de Infusão e para Seringas Hipodérmicas Estéreis de Uso Único, respectivamente. Available at: http://inmetro.gov.br/legislacao/rtac/pdf/ RTAC002666.pdf [Accessed: September 2020].

15. AssociaçãoBrasileira deNormasTécnicas (ABNT). ISO/IEC 17025. Requisitosgeraisparaacompetência de laboratório de ensaios e calibrações. Available at: https://pt.scribd.com/document/414735599/AbntNbr-Iso-17025 [Accessed: September 2020].

16. Instituto Nacional de Metrologia, Qualidade e Tecnologia (Inmetro). DOQ-CGCRE 0087. Orientações gerias sobre os requisitos da ABNT NBR ISO/IEC 17025:2017. Available at: http://www.inmetro.gov. br/credenciamento/eventos-cgcre/13-14-15Workshop/00-DOQ-CGCRE-087_rev_00_-_Orientacoes_ gerais_sobre_os_requisitos_da_ABNT_NBR_ISO_IEC_17025_2017.pdf [Āccessed: September 2020]. 
17. Instituto Nacional de Metrologia, Qualidade e Tecnologia (Inmetro). DOQ-CGCRE 0008. Orientação sobre validação de métodos analíticos. Available at: http://www.inmetro.gov.br/Sidoq/Arquivos/ CGCRE/DOQ/DOQ-CGCRE-8_01.pdf [Accessed: September 2020].

18. Magnusson, B; Örnemark, U. Eurachem Guide: The Fitness for Purpose of Analytical Methods. A Laboratory Guide to Method Validation and Related Topics, 2014, $2^{\text {nd }}$ Ed. Available at: https://www. eurachem.org/images/stories/Guides/pdf/MV_guide_2nd_ed_EN.pdf [Accessed: November 2020].

19. Barwick, V. Planning and Reporting Method Validation Studies. Supplement to Eurachem Guide on the Fitness for Purpose of Analytical Methods, 2019, $1^{\text {st }}$ Ed. Available at: https://eurachem.org/images/ stories/Guides/pdf/MV_Guide_planning_supplement_EN.pdf [Accessed: December 2020].

20. International Organization for Standardization. ISO 3696: Water for analytical laboratory use, Specification and test methods, 1987. Available at: https://www.iso.org/standard/9169.html [Accessed: May 2021].

21. Association of Official Agricultural Chemists (AOAC). Appendix D: Guidelines for Collaborative Study Procedures to Validate Characteristics of a Method of Analysis, 2002. Available at: https://members. aoac.org/AOAC_Docs/StandardsDevelopment/Collaborative_Study_Validation_Guidelines.pdf [Accessed: September 2020].

22. Miller, J. N.; Miller, J. C. Statistics and Chemometrics for Analytical Chemistry, $6^{\text {th }}$ Ed. Pearson, 2010, chapter 3, pp 49-52.

23. International Organization for Standardization (ISO). Uncertainty of Measurement. Guide to the Expression of Uncertainty in Measurement (GUM:1995), 2008. Available at: http://www.bipm.org/utils/ common/documents/jcgm/JCGM_100_2008_E.pdf [Accessed: May 2021].

24. Ellison, S. L. R; Wiliams, A. Eurachem/CITAC Guide CG4: Quantifying Uncertainty in Analytical Measurement. Available at: https://www.eurachem.org/images/stories/Guides/pdf/QUAM2012_P1.pdf [Accessed: May 2021].

25. Horwitz, W. Pure \& Appl. Chem., 1995, 67, pp 331-343. Available at: http://list.iupac.org/publications/ pac/1995/pdf/6702x0331.pdf [Accessed: May 2021].

26. Larrea-Marín, M. T.; Pomares Alfonso, M. S.; Gómez-Juaristi, M.; Sánchez-Muniz, F. J.; Ródenas de la Rocha, S. J. Food. Comp. Anal., 2010, 84, pp 814-820 (https://doi.org/10.1016/j.jfca.2010.03.015). 